\title{
Fast Sample Preparation Method Using Ultra-High Performance Liquid Chromatography Coupled to Tandem Mass Spectrometry for Natamycin Determination in Wine Samples
}

\author{
Gabrieli Bernardi, Tiele M. Rizzetti, Martha B. Adaime, Renato Zanella and \\ Osmar D. Prestes*
}
Laboratório de Análises de Resíduos de Pesticidas (LARP), Departamento de Química, Universidade Federal de Santa Maria, 97105-900 Santa Maria-RS, Brazil

\begin{abstract}
An easy and efficient sample preparation method was developed for the determination of natamycin residues in wine samples by solvent extraction and ultra-high performance liquid chromatography coupled to tandem mass spectrometry (UHPLC-MS/MS) analysis. After choosing acetonitrile as extraction solvent, an experimental design was carried out with different amounts of C18 and primary secondary amine (PSA) sorbents in order to optimize the clean-up step. Validation results were satisfactory, with recoveries from 77 to $95 \%$ and relative standard deviation (RSD) lower than $10 \%$ for the spike levels 5, 10 and $20 \mu \mathrm{g} \mathrm{L}^{-1}$. Method limit of detection (LOD) and quantification (LOQ) were 1.5 and $5.0 \mu \mathrm{g} \mathrm{L}^{-1}$, respectively. The validated method proved to be an excellent analytical tool, with a total analysis time of $3 \mathrm{~min}$. The method was applied in 10 Brazilian wine samples and no residues of natamycin were detected.
\end{abstract}

Keywords: natamycin, wine, sample preparation, UHPLC-MS/MS

\section{Introduction}

The use of preservatives in food and beverages is necessary to prevent or retard microbial growth avoiding undesirable alterations in the final product quality. Among the antimicrobial substances employed by the food industry, natamycin has been proven an effective alternative for controlling microbial growth. ${ }^{1}$ Natamycin or pimaricin is an antibiotic belonging to the group of polyene macrolides produced by actinomycetes Streptomyces natalensis. ${ }^{2,3}$ Several studies reported the use of natamycin for the surface treatment of cheeses and dry sausages ${ }^{4-6}$ and most recently, in antimicrobial packaging systems. ${ }^{7}$ Natamycin cannot be added to wines because it is classified as a non-permitted additive by the Code of Enological Practices of the International Organization of Vine and Wine (OIV). ${ }^{8}$ As a result, natamycin is forbidden in most countries, except in South Africa (30 $\left.\mathrm{mg} \mathrm{L}^{-1}\right)$, China (10 $\left.\mathrm{mg} \mathrm{L}^{-1}\right)$ and Argentina $\left(5 \mu \mathrm{g} \mathrm{L}^{-1}\right)$ where it is used as an alternative to sulfur dioxide during bottling, preventing refermentation in sweet and low acidity wines. ${ }^{9}$ However, export wines must comply with EU standards and currently a level of

*e-mail: osmar.prestes@ufsm.br
$5 \mu \mathrm{g} \mathrm{L}{ }^{-1}$ is enforced in countries as Germany. ${ }^{10}$ Recently, the European disease control authorities detected natamycin in wine samples from different producing countries and banned their sale and distribution. ${ }^{11,12}$ Besides addition to the wine, many wineries use natamycin on the walls and floors to eliminate the yeast and mold in the environment. Under these conditions, natamycin can be transferred into the wine being a contamination source.

In Brazil, the Brazilian Health Regulatory Agency (ANVISA) did not authorize the use of natamycin in wines, only on cheese surface with a maximum limit of $2 \mathrm{mg}$ per $100 \mathrm{~cm}^{2}$ and meat surface of embedded products with a maximum limit of $1 \mathrm{mg}$ per $\mathrm{dm}^{2} .{ }^{13}$ However, even the use of this not authorized compound, in the last years several wine samples were confiscated from Brazilian wineries due to the use of natamycin. ${ }^{14}$ Generally, the analytical methods for natamycin determination in food and beverages samples use organic solvents for extraction followed by filtration and determination by liquid chromatography. Roberts et al. ${ }^{15}$ developed a rapid procedure based on liquid chromatography coupled to high resolution mass spectrometry (LC-HRMS) for the determination of natamycin in wine samples. Sample preparation was conducted only by centrifugation in 
order to separate any particulate matter and filtration prior analysis. Alberts et al. ${ }^{10}$ used a liquid chromatographyelectrospray ionization tandem mass spectrometric method (LC-ESI-MS/MS) for the determination of natamycin in wine. Sample clean-up involves dilution followed by a solid phase extraction (SPE) step using aminopropyl SPE cartridges. Recoveries values were better than $80 \%$ with RSD $<10 \%$ while the method LOQ was $0.3 \mu \mathrm{g} \mathrm{L} \mathrm{L}^{-1}$ compliant with EU standards $\left(5 \mu \mathrm{g} \mathrm{L}{ }^{-1}\right)$. Repizo et al. ${ }^{16}$ used a similar approach for the natamycin determination in Argentinean wine varieties. In order to access the matrix effect, a cleanup through SPE procedure was performed using Oasis HLB cartridges and the results showed no substantial improvement of sensitivity. Thus, the samples were only filtered before injection into the LC-MS/MS system. Paseiro-Cerrato et al. ${ }^{17}$ developed a method for extraction of natamycin in different food samples such as cheese, sausages and wine. Methanol acidified with acetic acid was used for the extraction of natamycin from cheese and sausage while the wine samples were filtered and injected directly into the chromatograph without previous treatment. High performance liquid chromatographic with diodearray detection (HPLC-DAD) was used and the results were confirmed by LC-ESI-MS/MS in positive mode. No residues of natamycin were found in the samples and the method limit of detection (LOD) for wine was $10 \mu \mathrm{g} \mathrm{L}^{-1}$. Most recently, Sun et al. ${ }^{9}$ used SPE for the extraction of natamycin from wine samples. A weak anion exchange (WAX) SPE column exhibited better adsorption conditions for natamycin extraction in the method optimization. The elution was conducted using a formic acid, methanol/ water mixture and the resulted extract was injected into a LC-MS/MS for natamycin determination. Method limit of quantification (LOQ) was $3.34 \mu \mathrm{g} \mathrm{L}^{-1}$ and the recovery was in the range of 70-94\% with relative standard deviation (RSD) $\leq 4 \%$. Even achieving low detection limits, the existing extraction methods do not take into account a clean-up step prior injection. The use of clean-up becomes an important tool to prolong the equipment useful life, besides reduce the matrix effects when complex matrices, such as wine, are injected. ${ }^{18}$ In the last years, dispersive solid phase extraction (d-SPE) have been successfully used as clean-up technique in a large variety of matrices and analytes ${ }^{19-23}$ including wine samples. ${ }^{24-26}$ Besides, performing the extract dilution prior injection into ultrahigh performance liquid chromatography coupled to tandem mass spectrometry (UHPLC-MS/MS) system has proven to be a non-expensive alternative to reduce matrix effect and increase sensitivity. ${ }^{27}$

The aim of this study was to develop an extraction method for natamycin determination in wine samples using an efficient clean-up procedure to obtain a clean extract suitable for injection in the UHPLC-MS/MS system. In addition, the proposed method aims to be a fast procedure for use in routine laboratory analysis.

\section{Experimental}

\section{Reagents}

Neat standard of natamycin $(99.5 \%)$ was purchased from Sigma-Aldrich (USA). Ultrapure water was obtained in a Milli-Q Direct UV3 ${ }^{\circledR}$ system from Millipore (USA). The solvents, methanol and acetonitrile LC grade were acquired from Mallinckrodt (USA). Methanol was used to prepare the stock solution of $1000 \mathrm{mg} \mathrm{L}^{-1}$ of natamycin and acetonitrile the mobile phase. Formic and acetic acid p.a. grade were acquired from Sigma-Aldrich (USA) and J. T. Baker, respectively. The sorbents primary secondary amine (PSA) and C18 of $40 \mu \mathrm{m}$ were purchased from Agilent (USA). Nylon filters $(13 \mathrm{~mm})$ with porosity of $0.22 \mu \mathrm{m}$ obtained from Vertical Chromatography (Thailand) and glass vials with capacity of $2 \mathrm{~mL}$ purchased from Agilent (USA) were also used.

\section{Instrumentation}

General apparatus consisted in a vortex mixer model QL-901 from Microtécnica (Brazil), analytical balances AUW-220D and UX-420H from Shimadzu (Japan) and refrigerated centrifuge NT 825 acquired from Novatécnica (Brazil). An AcquityTM Ultra High Performance LC system purchased from Waters (USA) equipped with an autosampler, a binary pump and a column temperature controller coupled to a triple quadrupole mass spectrometer Xevo $\mathrm{TQ}^{\mathrm{TM}}$ model from Waters (USA) was used. Separation was performed by injecting $10 \mu \mathrm{L}$ into an Acquity BEH $\mathrm{C} 18$ column $(50 \times 2.1 \mathrm{~mm}, 1.7 \mu \mathrm{m})$ at $30^{\circ} \mathrm{C}$. The mobile phase was composed of (A) water and (B) acetonitrile, both containing $0.1 \%$ formic acid. The gradient program started at $5 \%$ of B (held $1.75 \mathrm{~min}$ ), then increased linearly to reach $100 \% \mathrm{~B}$ in $2.5 \mathrm{~min}$ (held $0.1 \mathrm{~min}$ ) and decreases to $5 \%$ of B at $2.6 \mathrm{~min}$, holding until $3 \mathrm{~min}$. The selected flow rate was $0.225 \mathrm{~mL} \mathrm{~min}^{-1}$ and the injection volume was $10 \mu \mathrm{L}$. Mass spectrometer operated with positive electrospray ionization (ESI) in selected reaction monitoring (SRM) mode. To choose the best fragments, a $0.05 \mathrm{mg} \mathrm{L}^{-1}$ natamycin solution was analyzed by direct infusion and two mass transitions were selected. The most intense transition was used for quantification and the other for identification. The data were acquired using MassLynx Mass Spectrometry Software from Waters (USA). MS source parameters were: capillary 
voltage, $2.0 \mathrm{kV}$; source temperature, $150{ }^{\circ} \mathrm{C}$; desolvation temperature, $500{ }^{\circ} \mathrm{C}$; desolvation gas $\left(\mathrm{N}_{2}\right)$ flow, $600 \mathrm{~L} \mathrm{~h}^{-1}$, cone gas $\left(\mathrm{N}_{2}\right)$ flow, $80 \mathrm{~L} \mathrm{~h}^{-1}$, and collision gas (Ar) with flow rate at $0.15 \mathrm{~mL} \mathrm{~min}^{-1}$.

\section{Sample preparation and clean-up optimization}

Based on previous published works ${ }^{15-17}$ and in the low solubility of natamycin in water, different organic solvents were tested aiming to extract this compound from wine samples. Since natamycin stability can be affected depending on sample $\mathrm{pH}$, the $\mathrm{pH}$ of the solvent used in this procedure was optimized. ${ }^{17}$ Therefore, methanol, methanol with $1 \%$ acetic acid, acetonitrile and acetonitrile with $1 \%$ acetic acid were evaluated as solvent extraction. Blank samples were spiked with natamycin at 10,20 and $50 \mu \mathrm{g} \mathrm{L}^{-1}$ and extracted with the different solvents $(\mathrm{n}=3)$. Results were evaluated according to the recoveries and RSD achieved in each test. After choosing the best extraction solvent, a clean-up step was introduced to the method in order to remove co-extractives before injection in the UHPLC-MS/MS system. Based on preliminary studies, the method optimization was conducted using a central composite design (CCD) with two factors. ${ }^{22,28}$ The sorbent amounts PSA and C18 were evaluated and natamycin recovery values were used as experimental response. The main factors used and their levels are shown in Table 1.

\section{Optimized extraction procedure}

The optimized extraction procedure consists in transfer $0.5 \mathrm{~mL}$ of wine sample to a $2 \mathrm{~mL}$ Eppendorf followed by the addition of $0.5 \mathrm{~mL}$ of acetonitrile to perform the extraction. The tube was vortexed for $30 \mathrm{~s}$ and the content was placed into a new tube containing C18 $(50 \mathrm{mg})$ and PSA $(100 \mathrm{mg})$. The tube was vortex for $1 \mathrm{~min}$ and then centrifuged for $4 \mathrm{~min}$ at $10000 \mathrm{rpm}$. After this step, the supernatant was collected, placed into a $2 \mathrm{~mL}$ vial and diluted $(5 \times)$ in ultrapure water before injection in the UHPLC-MS/MS system.

\section{Method validation}

For validation purposes, a blank sample was selected and the parameters selectivity, linearity, trueness, precision,
LOD and LOQ and matrix effect were evaluated. Linearity was evaluated using calibration curves in the range of 0.5 to $5 \mu \mathrm{g} \mathrm{L}-1$ prepared in acetonitrile and matrix matched extract, corresponding to the range of 5 to $50 \mu \mathrm{g} \mathrm{L}^{-1}$ in the sample, considering the method factor of 10 . Trueness was evaluated through recovery tests from blank samples spiked at 5, 10 and $20 \mu \mathrm{g} \mathrm{L}{ }^{-1}$ with seven extraction replicates performed for each spiked level. RSD results were used to determinate the method precision. Repeatability and intermediate precision of the method were evaluated through RSD $(n=7)$ by performing the analytical procedure at the same spiked levels on the same day and on different days, respectively. The method LOQ was obtained as the lowest spiked level that presented recoveries results between 70 and $120 \%$, with RSD $\leq 20 \%{ }^{29}$ and the method LOD was estimated dividing LOQm by $3.33 .^{30}$ Triphenylphosphate (TPP) and deuterated atrazine standards were used as internal standard and surrogate, respectively. Matrix effect was estimated comparing the slopes of the matrix matched calibration curves with those prepared in solvent (acetonitrile). The difference in the slopes of the matrix matched curves and the solvent curve were divided by the slope of the curve in solvent and was expressed as \% of matrix effect. ${ }^{29,31}$

\section{Results and Discussion}

\section{Optimization of the UHPLC-MS/MS system}

Based in others studies, 9,16 acetonitrile and water were chosen as the mobile phase. Formic acid $(0.1 \%$, v/v) was used as modifier in both aqueous and organic phases and provided the maximum response for the generation of the protonated molecule $[\mathrm{M}+\mathrm{H}]^{+}$. The elution gradient was mentioned in the Instrumentation section and the natamyicn retention time was obtained at $1.7 \mathrm{~min}$ with the total run time of $3 \mathrm{~min}$. SRM conditions were further optimized for the natamycin to obtain maximum sensitivity. The $1^{\text {st }}$ transition $(666.3>503.3, \mathrm{~m} / \mathrm{z})$ corresponds to the most abundant ion and was employed for quantification and the $2^{\text {nd }}$ transition $(666.3>485.2, \mathrm{~m} / \mathrm{z})$ was used as a qualitative ion for identification. The cone voltage, collision energy and ion ratio were $15 \mathrm{~V}, 11 \mathrm{~V}$ and $40 \%$, respectively. The structure, chemical proprieties and possible fragmentation pathway of natamycin are shown in Figure 1. This same fragmentation

Table 1. Responses for the designed matrix obtained by central composite design for clean-up optimization and natamycin extraction in wine samples

\begin{tabular}{|c|c|c|c|c|c|c|c|c|c|c|c|}
\hline \multirow{2}{*}{ Variable } & \multicolumn{11}{|c|}{ Assay } \\
\hline & 1 & 2 & 3 & 4 & 5 & 6 & 7 & 8 & 9 & 10 & 11 \\
\hline $\mathrm{C} 18 / \mathrm{mg}$ & 50 & 50 & 150 & 150 & 0 & 170 & 100 & 100 & 100 & 100 & 100 \\
\hline PSA / mg & 50 & 150 & 50 & 150 & 100 & 100 & 0 & 170 & 100 & 100 & 100 \\
\hline
\end{tabular}




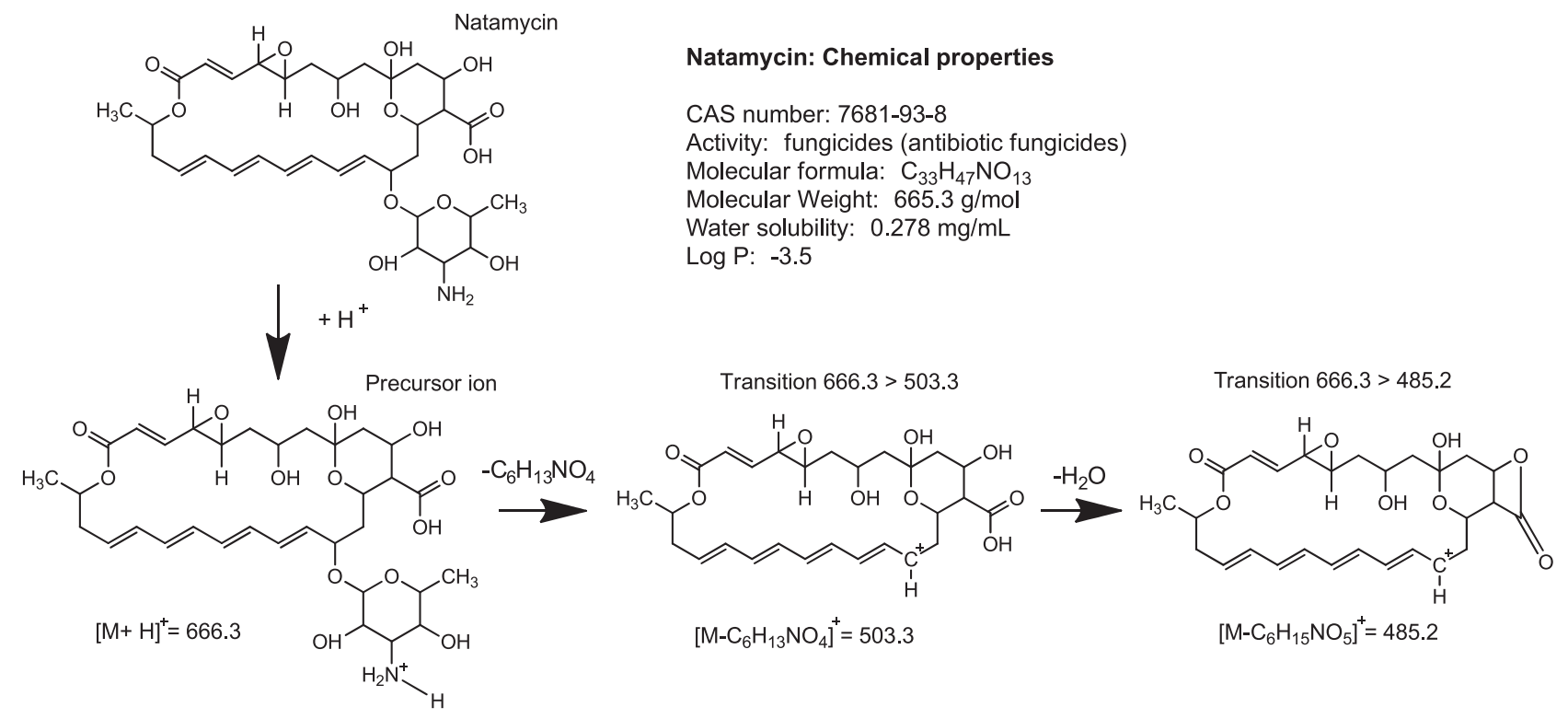

Figure 1. Structure, chemical properties and proposed MS/MS fragmentation pathway of natamycin (adapted from reference 16).

behavior was observed by Repizo et al. ${ }^{16}$ and Sun et al..$^{9}$ Figure S1 in the Supplementary Information shows the chromatogram obtained from the selected ions in SRM mode from a matrix matched standard solution at $5 \mu \mathrm{g} \mathrm{L}-1$.

\section{Sample preparation and clean-up optimization}

The extraction and clean-up steps for organic compounds determination are the most difficult steps in food analysis. The determination of natamycin in wine is usually conducted by direct injection of the sample into LC-MS/MS system. ${ }^{8,15}$ However, in this work, a solvent extraction was used in order to reduce the coextrative amounts that are transferred to the chromatography equipment when no sample preparation is used. Among the evaluated solvents, acetonitrile showed the best recovery results obtained in the average of $96 \%$, with $\mathrm{RSD} \leq 12 \%$ (Figure 2). Natamycin has a low solubility rate in methanol as reported as by Roberts et al. ${ }^{15}$ this fact may had interfered in the extraction process when this solvent was used. These results were better than those found using methanol as extraction solvent. When the acidified solvents were used, the variability among the replicates was more pronounced indicating an instability problem of natamycin structure at very low $\mathrm{pH}$ values. ${ }^{10}$

After choosing acetonitrile as extraction solvent, a central composite design was carried out for clean-up step optimization using d-SPE. Thus, the variables evaluated for d-SPE were the amounts of sorbents PSA and C18. PSA is used for the removal of acids, polar pigments and sugars while $\mathrm{C} 18$ is most used for the removal of lipid and non-polar components of the samples. ${ }^{32}$ Response surface

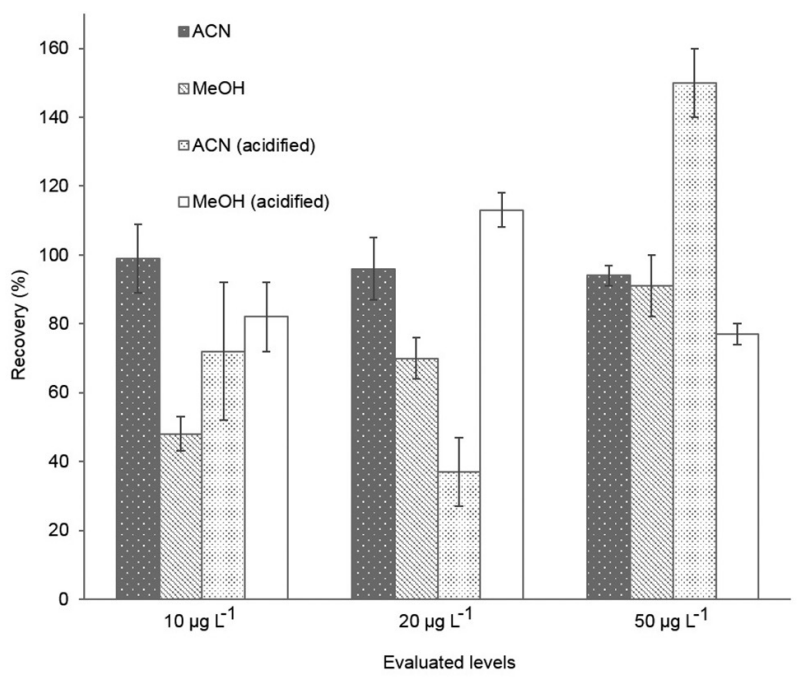

Figure 2. Optimization of the extraction solvents, acetonitrile, methanol, acetonitrile (1\% acetic acid) and methanol (1\% acetic acid) to determination of natamycin in wine samples at three fortification levels, $\mathrm{n}=3$.

methodology (RSM) was applied to evaluate the results and the variable dependent was the recovery (\%). ${ }^{22}$ Figure 3 shows that the combination of PSA and C18 provided satisfactory recovery and, as can be seen in the Figure 4, under this condition the co-extractives in the final extract are reduced when compared with only PSA. Thus, the chosen amounts for clean-up were $100 \mathrm{mg}$ of PSA and $50 \mathrm{mg}$ of $\mathrm{C} 18$ per $\mathrm{mL}$.

\section{Method validation}

According to the results (Table 2), natamycin showed good response in the range of 0.5 to $5 \mu \mathrm{g} \mathrm{\textrm {L } ^ { - 1 }}$ with good 


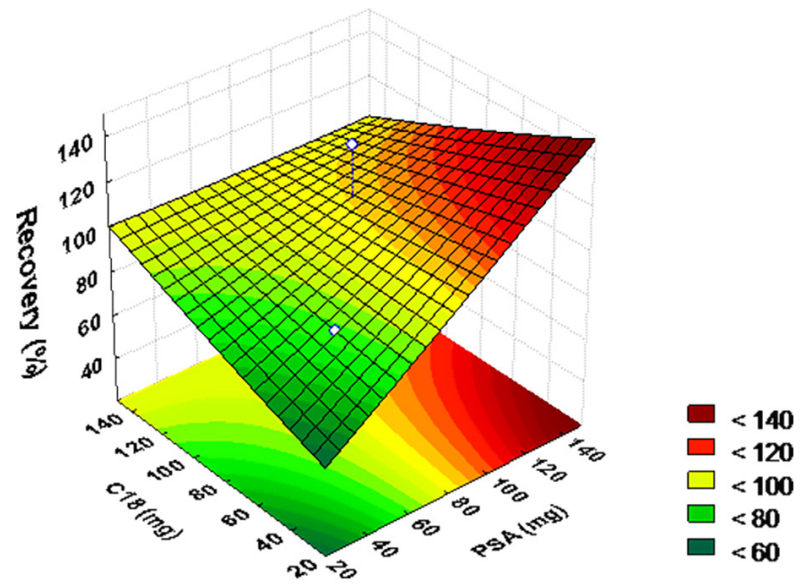

Figure 3. Response surface methodology considering natamycin recovery obtained with the CCD for the d-SPE clean-up in wine sample.

linearity, evidenced by the value of $r^{2}>0.99$. The precision, in terms of repeatability, evaluated at three concentration levels $\left(5,10\right.$ and $\left.20 \mu \mathrm{g} \mathrm{L}^{-1}\right)(\mathrm{n}=6)$, presented recoveries in the acceptable range of 77 to $95 \%$ and RSDr from 5 to $10 \%$. In terms of intermediate precision, the method shown recovery ranging from 79 to $92 \%$ with RSDip between 6 and $8 \%$. In this study, the method LOQ $\left(5.0 \mu \mathrm{g} \mathrm{L}^{-1}\right)$ obtained was adequated once this value is the maximum residue limit (MRL) established in the countries where natamycin control is conducted. ${ }^{16}$ The estimated LOD was $1.5 \mu \mathrm{g} \mathrm{L}^{-1}$. Matrix effects occur in the LC system when molecules coeluting with the compounds of interest altering the ionization efficiency of the electrospray interface..$^{33} \mathrm{~A}$ change in the chromatographic response above $20 \%$ means that the matrix effect starts to influence the analysis. ${ }^{29}$ In this study, even using d-SPE, a high value for matrix effect was found (-86\%). Red wine composition contains alcohol, organic acids, sugars and polyphenols such as anthocyanins, which play an important role in wine color. ${ }^{34}$ During ESI ionization some of these compounds can co-elute with the compound of interest and modify the ionization efficiency causing a signal suppression effect as can be seen in Supplementary Information (Figure S2). He et al..$^{35}$ also described a severe matrix effect $(>50 \%$ enhancement or supression) during pesticide residue analysis in wine samples through direct injection into the LC system. In order to compensate the matrix effect in this study, a matrix matched calibration curve was used for quantifications purposes. Deuterated atrazine and triphenylphosphate (TPP) were used in order to evaluate sample preparation performance and instrumental response, respectively.

\section{Real samples}

The validated procedure was applied to determination of natamycin in 10 different varieties of Brazilian wine obtained in the local market. No residues of natamycin were detected in any of the analyzed samples considering the LODm of this method. A possible explanation to this fact is that ANVISA has forbidden the use of natamycin in wine and, as a result, the wineries are more careful in use this compound. Besides that, Sun et al. ${ }^{9}$ reported that natamycin can degradate during wine making process even when added in further steps like malo-lactic fermentation, clarification and storage. The results found are the same reported by Repizo et al. ${ }^{16}$ Also, Paseiro-Cerrato et al. ${ }^{17}$ did not found natamycin residues in wine samples from Spain and Argentina.
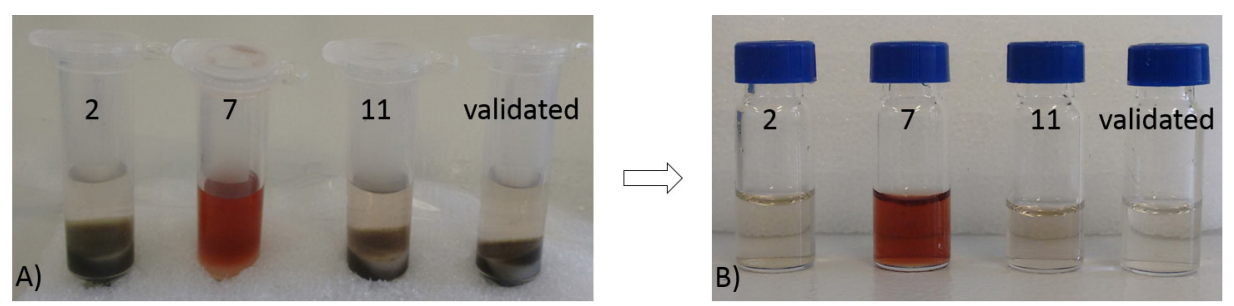

Figure 4. Co-extratives removal efficiency demostrated by the assays 2, 7, 11 and the validated procedure obtained by CCD with the use of differents quantities of PSA and C18. (A) Before centrifugation and filtration and (B) after filtration step.

Table 2. Results of trueness (recovery), precision (repeatability, intermediate precision), matrix effect, linearity, LOD and LOQ of the validated method by UHPLC-MS/MS

\begin{tabular}{|c|c|c|c|c|c|c|c|c|c|c|}
\hline \multirow{3}{*}{ Analyte } & \multicolumn{6}{|c|}{ Spike levels / $\left(\mu \mathrm{g} \mathrm{L}^{-1}\right)$} & \multirow{3}{*}{$\begin{array}{c}\text { Matrix } \\
\text { effect / \% }\end{array}$} & \multirow{3}{*}{$\begin{array}{c}\text { Linearity } \\
\left(\mathrm{r}^{2}\right)\end{array}$} & \multirow{3}{*}{$\begin{array}{l}\mathrm{LOD} / \\
\left(\mu \mathrm{g} \mathrm{L}^{-1}\right)\end{array}$} & \multirow{3}{*}{$\begin{array}{c}\mathrm{LOQ} / \\
\left(\mu \mathrm{g} \mathrm{L}^{-1}\right)\end{array}$} \\
\hline & 5 & 10 & 20 & 5 & 10 & 20 & & & & \\
\hline & \multicolumn{3}{|c|}{$\operatorname{Rec}(\operatorname{RSDr})^{\mathrm{a}} / \%$} & \multicolumn{3}{|c|}{$\operatorname{Rec}($ RSDip) $/ \%$} & & & & \\
\hline Natamycin & $86(10)$ & $77(6)$ & $95(5)$ & $80(8)$ & $79(6)$ & $92(8)$ & -86 & 0.995 & 1.5 & 5.0 \\
\hline
\end{tabular}

${ }^{\mathrm{a}}=7$. 


\section{Conclusions}

In this study, a simple extraction procedure was developed to permit the extraction of natamycin from wine samples and analysis in UHPLC-MS/MS. The best trueness and precision results were obtained when acetonitrile was used as extraction solvent, employing a clean-up step with d-SPE using PSA and C18 sorbents, to minimize the effects in chromatographic system. A low LOQ $\left(5.0 \mu \mathrm{g} \mathrm{L}^{-1}\right)$ was achieved with a combination of a quick and effective extraction procedure and a fast and sensitive determination by UHPLC-MS/MS system, resulting in a total of $3 \mathrm{~min}$ for execution. Thus, the validated method can be applied in routine analysis to natamycin determination in wine samples from different varieties.

\section{Supplementary Information}

Supplementary data are available free of charge at http://jbcs.sbq.org.br as PDF file.

\section{Acknowledgments}

The authors are grateful to the Brazilian agencies CNPq, CAPES, FAPERGS and FINEP for the financial support and fellowships.

\section{References}

1. Fuciños, C.; Fuciños, P.; Fajardo, P.; Amado, I. R.; Pastrana, L. M.; Rúa, M. L.; Food Biop. Technol. 2015, 8, 1583.

2. Stark, J. In Encyclopedia of Food Microbiology; Batt, C.; Patel, P. D.; Robinson, R. K., eds.; Academic: San Diego, 1999, p. 1776.

3. Koontz, J. L.; Marcy, J. E.; J. Agric. Food Chem. 2003, 51, 7106.

4. Delves-Broughton, J.; Thomas, L. V.; Williams, G.; Food Aust. 2006, 58, 19.

5. Ollé-Resa, C. P.; Jagus, R. J.; Gerschenson, L. N.; Food Control 2014, 35, 101

6. Dalhoff, A. A. H.; Levy, S. B.; Int. J. Antimicrob. Agents 2015, 45, 564.

7. Lantano, C.; Alfieri, I.; Cavazza, A.; Corradini, C.; Lorenzi, A.; Zucchetto, N.; Montenero, A.; Food Chem. 2014, 165, 342.

8. Method OIV-MA-AS323-09; Determination of Natamycin in Wines (Résolution OIV-SCMA 461-2012); Compendium of International Methods of Analysis of Wines and Musts (2 vol.): Paris, 2012. Available at http://www.oiv.int/public/medias/2588/ oiv-ma-as323-09.pdf, accessed in August 2016.

9. Sun, X.; Li, X.; Wang, P.; Ma, T.; Huang, W.; Han, S.; Zhan, J.; Food Chem. 2016, 194, 928.
10. Alberts, P.; Stander, M. A.; de Villiers, A.; S. Afr. J. Enol. Vitic. 2011, 32, 51 .

11. EFSA Panel on Food Additives and Nutrient Sources added to Food (ANS); EFSA J. 2009, 7, 1412.

12. EU; European Parliament and Council Directive No. 95/2/EC of 20 February 1995 on Food Additives other than Colours and Sweeteners Off; Official Journal, 1995.

13. Agencia Nacional de Vigilância Sanitária (ANVISA); Resolução CNS/MS No. 04, de 24 de novembro de 1988. Available at http://www.sucodeuvadobrasil.com.br/legislacao/ Res_04_CNS.pdf, accessed in June 2016.

14. http://www.agricultura.gov.br/vegetal/noticias/2014/05/mapaautua-industrias-de-vinhos-no-rio-grande-do-sul, accessed in June 2016.

15. Roberts, D. P. T.; Scotter, M. J.; Godula, M.; Dickinson, M.; Charlton, A. J.; Anal. Methods 2011, 3, 937.

16. Repizo, L. M.; Martinez, L. D.; Olsina, R. A.; Cerutti, S.; Raba, J.; Anal. Bioanal. Chem. 2012, 402, 965

17. Paseiro-Cerrato, R.; Otero-Pazos, P.; de Quirós, A. R.; Sendón, R.; Angulo, I.; Paseiro-Losada, P.; Food Control 2013, 33, 262.

18. Arias, J. L. O.; Rombaldi, C.; Caldas, S. S.; Primel, E. G.; J. Chromatogr. A 2014, 1360, 66.

19. González-Curbelo, M. A.; Socas-Rodríguez, B.; HerreraHerrera, A. V.; González-Sálamo, J.; Hernández-Borges, J.; Rodríguez-Delgado, M. Á.; TrAC, Trends Anal. Chem. 2015, $71,169$.

20. Myresiotis, C. K.; Temtespasis, S.; Vryzas, Z.; Karaoglanidis, G. S.; Food Chem. 2015, 182, 81.

21. Delgado-Zamarreño, M. M.; Fernández-Prieto, C.; BustamanteRangel, M.; Pérez-Martín, L.; Food Chem. 2016, 192, 825.

22. Rizzetti, T. M.; Kemmerich, M.; Martins, M. L.; Prestes, O. P.; Adaime, M. B.; Zanella, R.; Food Chem. 2016, 196, 25.

23. Volpatto, F.; Wastowski, A. D.; Bernardi, G.; Prestes, O. D.; Zanella, R.; Adaime, M. B.; J. Braz. Chem. Soc. 2016, DOI: http://dx.doi.org/10.5935/0103-5053.20160032.

24. Romero-González, R.; Garrido Frenich, A.; Martínez Vidal, J. L.; Prestes, O. D.; Grio, S. L.; J. Chromatogr. A 2011, 1218, 1477.

25. Valente, I. M.; Santos, C. M.; Moreira, M. M.; Rodrigues, J. A.; J. Chromatogr. A 2013, 127, 27.

26. Payá, P.; Mulero, J.; Oliva, J.; Cámara, M. A.; Barba, A.; Food Chem. Toxicol. 2013, 60, 419.

27. Li, H.; Wang, C.; Zhu, Q.; Du, H.; Guan, S.; Wang, F.; Zhang, W.; Fan, W.; Chen, Z.; Yang, G.; Aboul-Enein, H. Y.; Anal. Methods 2016, 8, 5061.

28. Kemmerich, M.; Rizzetti, T. M.; Martins, M. L.; Prestes, O. D.; Adaime, M. B.; Zanella, R.; Food Anal. Methods 2015, 8, 728.

29. European Commission; Guidance Document on Analytical Quality Control and Validation Procedures for Pesticide Residues Analysis in Food and Feed; document No. SANTE/11945/2015, 2015. 
30. Orso, D.; Martins, M. L.; Donato, F. F.; Rizzetti, T. M.; Kemmerich, M.; Adaime, M. B.; Zanella, R.; J. Braz. Chem. Soc. 2014, 25, 1355.

31. Kruve, A.; Leito, I.; Herodes, K.; Anal. Chim. Acta 2009, 651, 75.

32. Cabrera, L. C.; Caldas, S. S.; Prestes, O. D.; Primel, E. G.; Zanella, R.; J. Sep. Sci. 2016, 39, 1945.

33. Ferrer, C.; Lozano, A.; Agüera, A.; Girón, A. J.; Fernández-Alba, A. R.; J. Chromatogr. A 2011, 1218, 7634.
34. Alberts, P.; Stander, M. A.; de Villiers, A.; J. Chromatogr. A 2012, 1235, 92.

35. He, Z.; Xu, Y.; Wang, Lu.; Peng, Y.; Luo, M.; Cheng, H.; Liu, X.; Food Chem. 2016, 196, 1248.

Submitted: June 29, 2016

Published online: August 15, 2016 